\title{
Influence of the ozone profile above Madrid (Spain) on Brewer estimation of ozone air mass factor
}

\author{
M. Antón ${ }^{1,2}$, M. López ${ }^{3}$, M. J. Costa ${ }^{2,4}$, A. Serrano ${ }^{1}$, D. Bortoli ${ }^{2}$, M. Bañón ${ }^{3}$, J. M. Vilaplana ${ }^{5}$, and A. M. Silva $a^{2,4}$ \\ ${ }^{1}$ Departamento de Física, Universidad de Extremadura, Badajoz, Spain \\ ${ }^{2}$ Geophysics Centre of Évora (CGE), University of Évora, Évora, Portugal \\ ${ }^{3}$ Agencia Estatal de Meteorología (AEMET), Madrid, Spain \\ ${ }^{4}$ Department of Physics, University of Évora, Évora, Portugal \\ ${ }^{5}$ Estación de Sondeos Atmosférico "El Arenosillo", Instituto Nacional de Técnica Aeroespacial (INTA), Huelva, Spain
}

Received: 22 June 2009 - Revised: 5 August 2009 - Accepted: 6 August 2009 - Published: 14 August 2009

\begin{abstract}
The methodology used by Brewer spectroradiometers to estimate the ozone column is based on differential absorption spectroscopy. This methodology employs the ozone air mass factor (AMF) to derive the total ozone column from the slant path ozone amount. For the calculating the ozone AMF, the Brewer algorithm assumes that the ozone layer is located at a fixed height of $22 \mathrm{~km}$. However, for a real specific site the ozone presents a certain profile, which varies spatially and temporally depending on the latitude, altitude and dynamical conditions of the atmosphere above the site of measurements. In this sense, this work address the reliability of the mentioned assumption and analyses the influence of the ozone profiles measured above Madrid (Spain) in the ozone AMF calculations. The approximated ozone AMF used by the Brewer algorithm is compared with simulations obtained using the libRadtran radiative transfer model code. The results show an excellent agreement between the simulated and the approximated AMF values for solar zenith angle lower than $75^{\circ}$. In addition, the relative differences remain lower than $2 \%$ at $85^{\circ}$. These good results are mainly due to the fact that the altitude of the ozone layer assumed constant by the Brewer algorithm for all latitudes notably can be considered representative of the real profile of ozone above Madrid (average value of $21.7 \pm 1.8 \mathrm{~km}$ ). The operational ozone AMF calculations for Brewer instruments are limited, in general, to SZA below $80^{\circ}$. Extending the usable SZA range is especially relevant for Brewer instruments located at high mid-latitudes.
\end{abstract}

Keywords. Atmospheric composition and structure (Transmission and scattering of radiation)

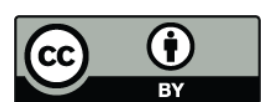

Correspondence to: M. Antón (mananton@unex.es)

\section{Introduction}

The well-established world wide network of Brewer and Dobson spectroradiometers is generally considered as the standard reference for the remote sensing of the vertically integrated ozone amount (named total ozone column, hereafter denoted as TOC) from the Earth's surface. These instruments measure direct sunlight intensities at standard wavelengths falling within the Huggins band where the ozone absorption increases rapidly with decreasing wavelength. The integrated ozone amount along the light path (slant path ozone amount) is derived from differential absorption spectroscopy techniques which are described in several reference works, (e.g., Basher, 1982; Kerr et al., 1984; Komhyr et al., 1989; Kerr, 2002). The TOC values are directly obtained from the ratio between the slant path ozone amount and the ozone air mass factor (AMF).

The expression used by the Brewer algorithm for calculating the ozone AMF values assumes that the ozone layer is located at a fixed height $(22 \mathrm{~km})$ (Savastiouk and McElroy, 2004). This approximation leads to errors in ozone AMF calculations, which are particularly relevant at large SZA (Bernhard et al., 2005; Redondas and Cede, 2005). In general, ozone AMF depends on a number of factors, mainly: solar elevation, the profile of the ozone layer, and the wavelength. The effects of these variables have been examined in some detail for zenith-sky geometry (Perliski and Solomon, 1993; Sarkissian et al., 1995; Slusser et al., 1996). In contrast, there are only few studies that analyse the accuracy of the ozone AMF calculations for direct sun measurements from ground-based spectrophotometers. Among them, Bernhard et al. (2005) showed that systematic errors caused by ozone AMF calculations in Dobson instruments may exceed 2\% for SZA larger than $80^{\circ}$. Redondas and Cede (2005) found that the total ozone column derived from Brewer instruments 
is underestimated by $0.4 \%$ at $\mathrm{SZA}=80^{\circ}$ for each kilometre that the actual altitude of the ozone layer exceeds $22 \mathrm{~km}$. In this framework, the main goal of this article is to analyse the relative accuracy of the ozone AMF approximation derived from Brewer instruments using AMF values calculated by means of the libRadtran radiative transfer model (Mayer and Kylling, 2005) and real ozone profiles measured above Madrid (Spain) as inputs for the simulations.

The instrumentation and the data used in this paper are described in Sect. 2. Section 3 describes the methodology followed in the sensitivity analysis. Section 4 presents and discusses the results obtained in this work and, finally, Sect. 5 summarizes the main conclusions.

\section{Instrumentation}

\subsection{Brewer spectroradiometer}

The Brewer spectrophotometer is a fully automatic instrument that measures total ozone column in the atmosphere by observations of direct spectral irradiances of solar radiation at four fixed wavelengths in the UV region, nominally $310.0 \mathrm{~nm}, 313.5 \mathrm{~nm}, 316.8 \mathrm{~nm}$ and $320.0 \mathrm{~nm}$, with full-width half-intensity (FWHI) resolution of about $0.6 \mathrm{~nm}$. Calculation of total ozone column (TOC) from the differential absorption spectroscopy technique can be expressed by the following general relation (Vanicek, 2006):

$\mathrm{TOC}=\left(F_{o}-F-\beta m p / p_{0}\right) / \alpha \mu$

where $F$ and $F_{0}$ are linear combinations of logarithms of the direct normal irradiance at the surface and extraterrestrial irradiance, respectively, $\alpha$ and $\beta$ are linear combinations of ozone absorption and Rayleigh molecular scattering coefficients at the same wavelengths, $\mu$ is the relative optical air masses of the ozone layer (the ozone AMF) and $m$ the relative optical air mass corresponding to Rayleigh scattering, and $p$ and $p_{0}$ are the observed and mean sea air pressures. The use of this method allows for the removal of the effects of aerosols and sulphur dioxide from the ozone retrievals.

\subsection{Ozonosondes}

Ozonesonde profiles obtained between 1995 and 2008 at Madrid $\left(40.47^{\circ} \mathrm{N}, 3.58^{\circ} \mathrm{W}, 631 \mathrm{~m}\right)$ have been included in this work as input in the radiative transfer model simulations. The ozone profile measurements were made by balloon-borne ozonesondes employing an Electrochemical Concentration Cell (ECC) sensor (Komhyr, 1969). In this cell, the electrical current is directly related to the uptake rate of ozone in the cathode chamber. The subtype of ECC ozonesondes used at Madrid is 6a sonde manufactured by Science Pump Corporation, Camden, New Jersey. The ozonesondes have been interfaced to Vaisala RS80-15G radiosondes. The balloons ascended to a maxima altitude of $37 \mathrm{~km}$.

\section{Methodology}

\subsection{The ozone air mass derived from Brewer algorithm}

The ozone AMF is defined as the ratio of the actual (slant) ozone path length taken by the direct solar beam to the analogous vertical ozone path when the Sun is overhead from the surface to the top of the atmosphere. It can be expressed by (Thomason et al., 1983):

$$
\mu(\theta, \lambda)=\frac{1}{\int_{z o}^{\infty} \sigma_{\lambda}(z) d z} \int_{z o}^{\infty} \frac{\sigma_{\lambda}(z) d z}{\left[1-\frac{n_{0}}{n(z)}\left(\frac{z_{0}}{z}\right)^{2} \sin ^{2} \theta_{o}\right]^{1 / 2}}
$$

where $\sigma_{\lambda}(z)$ is the unit volume extinction coefficient of the ozone $\left(\mathrm{km}^{-1}\right)$ as a function of altitude $z$ at wavelength $\lambda$, $n(z)$ is the complex index of refraction of air at altitude $z, \theta_{0}$ is the apparent SZA at which the Sun appears at the Earth's surface, and $n_{0}$, and $z_{0}$ are the values of the respective variables at the earth's surface. If the following three approximations are assumed: (1) ozone layer is a delta function at a fixed altitude $h$ above sea level, (2) the dependence of the index of refraction on altitude is neglected, being the index of refraction of air at altitude $h$ equal to the index of refraction at surface $\left(n_{0}=n_{h}\right)$, and (3) the apparent SZA is equal to the true SZA $(\theta)$, then Eq. (2) can be approximated to (Berhard et al., 2005):

$u(\theta)=\frac{1}{\sqrt{1-\frac{(R+r)^{2}}{(R+h)^{2}} \operatorname{Sin}^{2} \theta}}$

where $R$ is the radius of the Earth, and $r$ is altitude of the station.

This last expression is used by the Brewer algorithm with a fixed value of 0.99656 for $(R+r) /(R+h)$. Using a mean radius of the Earth of $6370 \mathrm{~km}$ and a null altitude for groundbased station, the Brewer algorithm assumes an ozone layer $21.988 \mathrm{~km}$ above the station.

\subsection{Calculation of the ozone air mass from radiative transfer model}

The Beer-Lambert law describes how an incident beam of radiation is attenuated by scattering and absorption within the atmosphere. Assuming the hypothesis of additivity of these atmospheric processes, the Lambert Beer law may be written for a single absorber (ozone in our case) as:

$L_{\lambda}=L_{\lambda 0} \exp \left(-\tau_{O_{3}} \mu\right)$

where $L_{\lambda}$ is the radiance at the earth's surface already attenuated by single scattering and ozone absorption at wavelength $\lambda, L_{\lambda 0}$ is the radiance after attenuation caused by scattering only, and $\tau_{O 3}$ is the vertical optical thickness of ozone. Thus, physically, the ozone AMF represents the effective increase in the ozone optical path due to the slant path of the radiation with respect to the vertical direction. 
Attenuation of the direct-solar irradiance through the atmosphere can be also described by the Beer-Lambert law (Iqbal, 1983). Thus, in this work, the ozone AMF is calculated using the inversion of Eq. (4) (Noxon et al., 1979; Solomon et al., 1987; Masquard et al., 2000), given by:

$\mu=\frac{\ln \left(\frac{E_{\lambda 0}}{E_{\lambda}}\right)}{\tau_{\mathrm{O}_{3}}}$,

where the direct spectral irradiances $E_{\lambda}$ and $E_{\lambda 0}$ are simulated by the libRadtran radiative transfer model (Mayer and Kylling, 2005). These direct spectral irradiances were obtained using a pseudo spherical radiative transfer equation solver (sdisort) with 16 streams mode and standard atmosphere midlatitude summer (afglms). Thus, for deriving the ozone AMF from expression (5), two model simulations must be performed: one simulation where the ozone amount is included to determine $E_{\lambda}$ and a second simulation where this absorber is omitted from the model atmosphere to determine $E_{\lambda 0}$. The vertical optical thickness of ozone must be introduced as input in the first simulation.

\section{Results and discussion}

The main hypothesis assumed in the Brewer algorithm for calculating the ozone AMF (expression 3) is that the ozone distribution is confined to a delta layer at a fixed altitude of $22 \mathrm{~km}$. However, the real ozone AMF values depend on the profile of the ozone layer which, in turn, depends on the latitude, altitude and dynamical conditions (mainly in the low and middle stratosphere) at the observer's location. In order to quantify the effect of the Brewer approximation at middle latitudes, we simulate the ozone AMF values using Eq. (5) with the monthly averages of the real ozone profiles measured at Madrid as inputs in the simulations.

The dependence of the ozone AMF with respect to the wavelength in Eq. (5) is very small in the interval used by the Brewer instruments (between 310 and $320 \mathrm{~nm}$ ) (Bernhard et al., 2005). Also, although ozone can be optically thick in the stratosphere, its air mass factor does not depend on the total amount of the absorber. In this sense, all ozone AMF simulations are based on a fixed wavelength of $310 \mathrm{~nm}$ and on a fixed TOC value of $300 \mathrm{DU}$. The ozone profiles are rescaled according to this TOC value.

Figure 1 (top) shows the comparison between the approximation used by the Brewer algorithm for calculating the ozone AMF (Eq. 3) and the simulated AMF values (Eq. 5) using the monthly averaged ozone profiles as inputs to the radiative model. This plot indicates that the approximated ozone AMF expression and the simulated one are in good agreement for zenith angles up to $85^{\circ}$, but for higher zenith angles the expression used in Brewer algorithm gives smaller values of ozone AMF which leads to an overestimation of the total ozone column (see Eq. 1). In addition, Figure 1
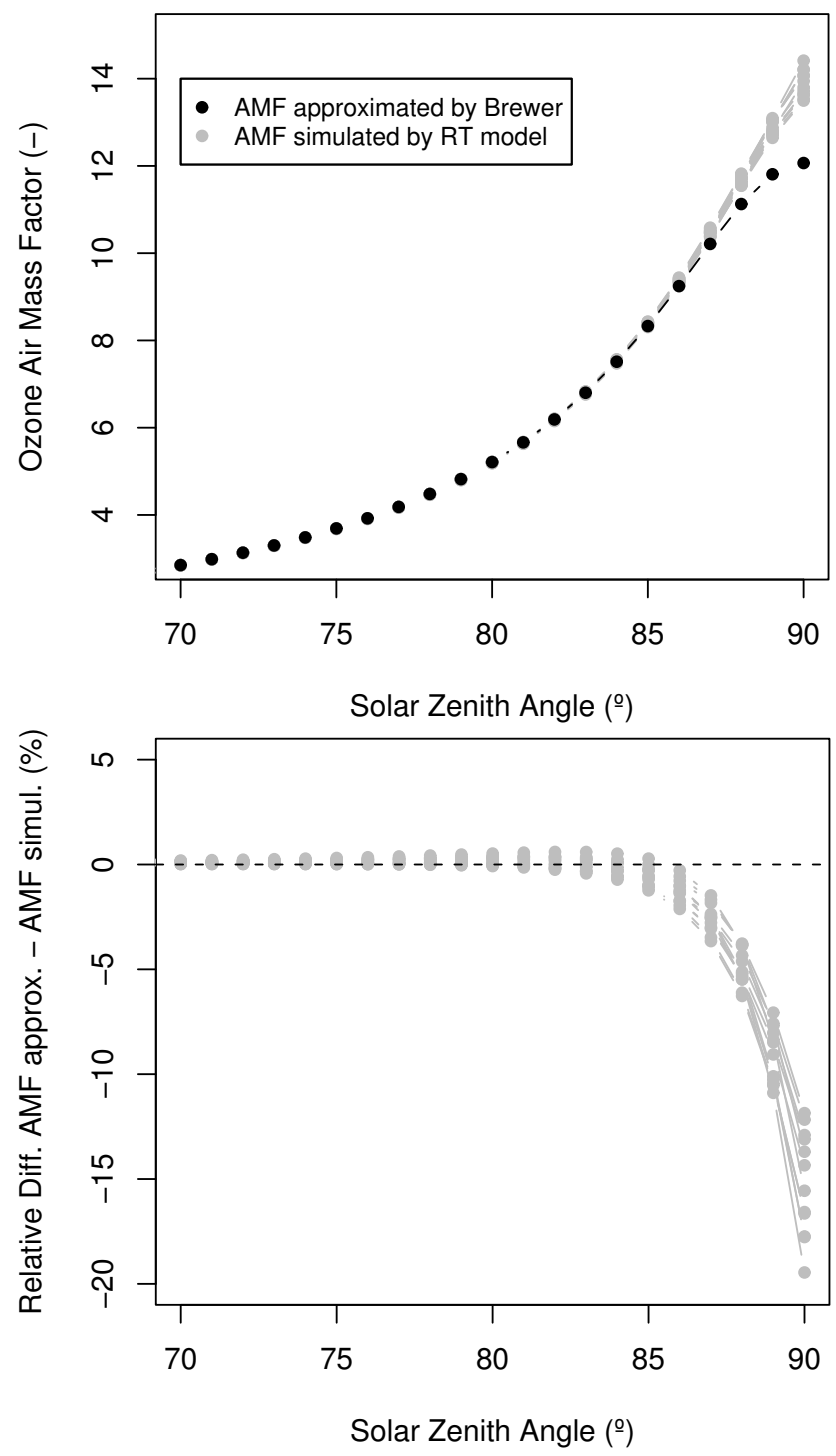

Fig. 1. Top: dependence of the ozone air mass factor (AMF) calculated by the Brewer algorithm (in black) and simulated with the libRadtran model for each month (in grey) with respect to the solar zenith angle. Bottom: relative differences between the approximated and simulated ozone AMF as a function of the solar zenith angle.

(bottom) shows the relative differences between the approximated and simulated values (AMF $\left.{ }^{a p p r}-\mathrm{AMF}^{\mathrm{sim}} / \mathrm{AMF}^{\mathrm{appr}}\right)$ as a function of the SZA. It can be seen tat these relative differences are negligible for SZA smaller than $75^{\circ}$. The differences between the approximated and simulated ozone AMF values are smaller than $2 \%$ at $85^{\circ}$, rapidly increasing to 10 $20 \%$ at $90^{\circ}$. The results show no significant seasonal differences between the approximated and simulated ozone AMF values. 


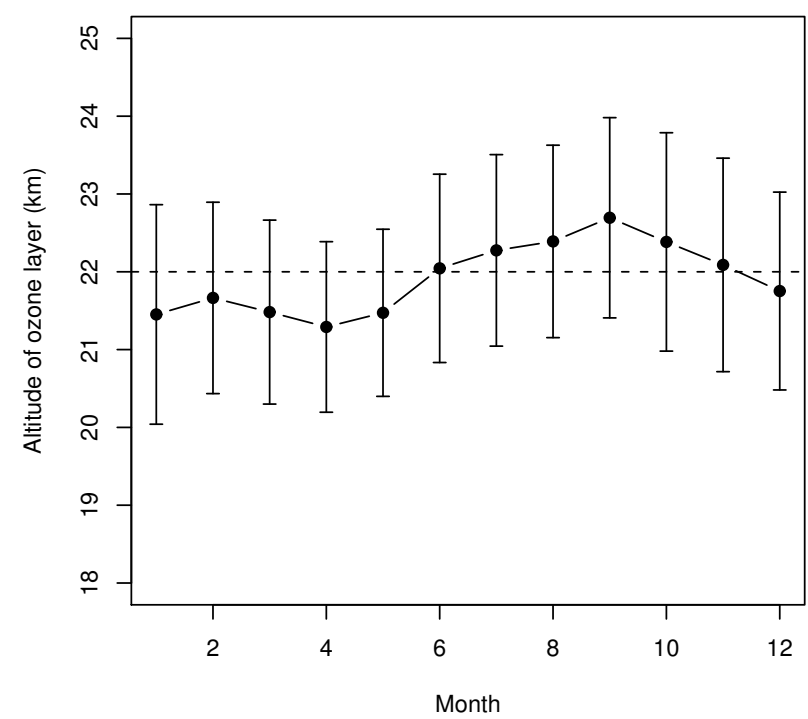

Fig. 2. The monthly mean evolution of the ozone layer altitude (Eq. 6) above Madrid (Spain), considering data between 1995 and 2008. The error bars correspond to \pm two standard deviation.

Each profile of the ozone distribution may be characterized through the altitude of its mass centre (hereafter altitude of the ozone layer). This altitude is obtained from the following expression:

$h_{c m}=\frac{\sum_{i=0}^{n}\left[\mathrm{O}_{3}\right]_{i} h^{i}}{\sum_{i=0}^{n}\left[\mathrm{O}_{3}\right]_{i}}$

where $\left[\mathrm{O}_{3}\right]_{i}$ is the ozone concentration measured at the altitude $h_{i}$ during each ozonesonde. In this work, the altitude of the ozone layer is only calculated for the balloons that reach an altitude higher than $32 \mathrm{~km}$ ( 351 cases of 473 in all). Thus, it is found that the average altitude ( \pm 2 standard deviation) of the ozone layer over Madrid is $21.7 \pm 1.8 \mathrm{~km}$.

In order to compare the experimental altitude of the ozone distribution with respect to the simplification assumed by the Brewer algorithm, the Fig. 2 shows the monthly variation of the ozone layer altitude over Madrid, for the period 1995 to 2008 , together with the constant value of $22 \mathrm{~km}$ assumed in the Brewer expression. The error bars correspond to \pm two standard deviation. It can be seen that, since the seasonal evolution of the ozone altitude is of lower magnitude than the monthly intra-variability above Madrid, the constant altitude can be considered representative all throughout the year. The relative differences between the true monthly altitudes of the ozone layer and the fixed value are between $-3.2 \%$ for April and $+3.1 \%$ for September. This fact clearly explains the good agreement between the simulated and the approximated ozone AMF values shown in the two plots of Fig. 1. In addition, the seasonal variation shown in this figure is in

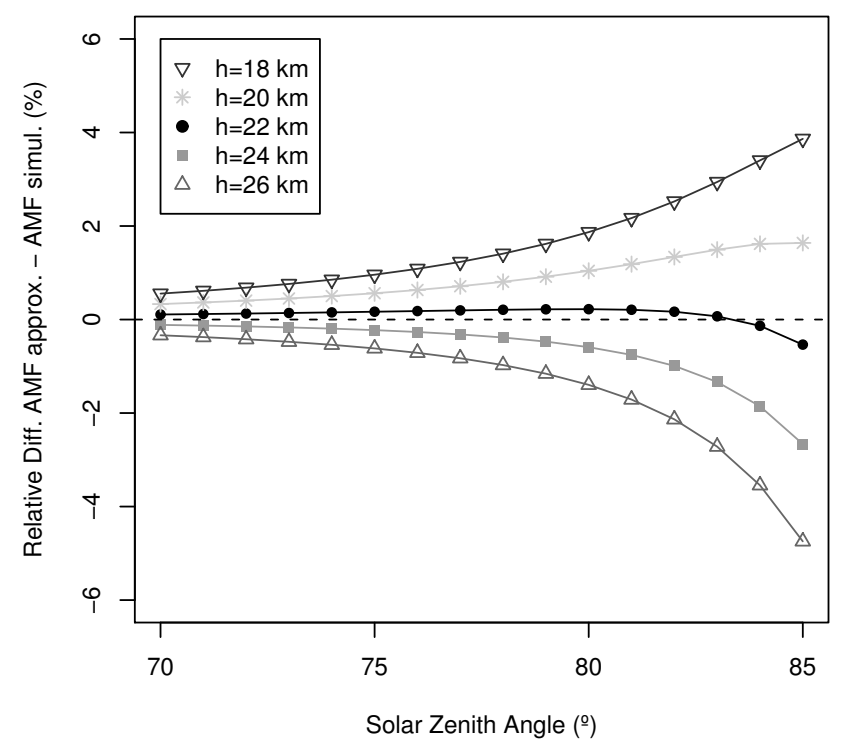

Fig. 3. Relative differences between the approximated ozone air mass factor (AMF) by the Brewer algorithm using five altitudes for the ozone layer $(18,20,22,24,26 \mathrm{~km})$ and the simulated ozone AMF using the average ozone profile in June as a function of the solar zenith angle.

good agreement with the ozone pattern typical of the middle latitudes. Thus, the higher altitudes of the ozone layer are recorded during summer and autumn.

Finally, we analyse the effects of altitude changes on the expression used by the Brewer algorithm (Eq. 3). In this sense, Fig. 3 shows the relative differences between the simulated ozone AMF values using the average ozone profile for June and the approximated AMF values using altitudes of 18 , $20,22,24$ and $26 \mathrm{~km}$. The lower relative differences $(<0.5 \%)$ are obtained for the case of altitude $22 \mathrm{~km}$. This result agrees with the fact that the average altitude value of ozone layer over Madrid for June is $22.0 \pm 1.2 \mathrm{~km}$. In addition, the relative differences between the simulated and approximated AMF values increases with the variation of altitude with respect to the reference case of the $22 \mathrm{~km}$. Thus, the relative difference between ozone AMF approximated with $h=18 \mathrm{~km}$ and approximated with $h=22 \mathrm{~km}$ reaches $+5 \%$ at SZA $\sim 85^{\circ}$. This result agrees with the work of Bernhard et al. (2005) which showed an overestimation of the true ozone AMF using the Dobson algorithm assuming the ozone layer at $17 \mathrm{~km}$.

In the framework of the Sodankylä Total Column Ozone Intercomparison (SAUNA), Redondas and Cede (2005) showed that the relative uncertainty in the Brewer total ozone retrieval is reduced from $\sim 3 \%$ to below $2 \%$ using climatological data for the altitude of the ozone layer instead of a fixed value $(22 \mathrm{~km})$. In addition, these authors found that the total ozone column derived from Brewer instruments is underestimated by $0.4 \%$ at $\mathrm{SZA}=80^{\circ}$ for each kilometre that the actual altitude of the ozone layer exceeds $22 \mathrm{~km}$. These 
results are related to the fact that the climatological altitude of the ozone layer above Sodankylä (Finland) is notably different from the fixed value of $22 \mathrm{~km}$ assumed by the Brewer instrument. In contrast, we have obtained the seasonal behaviour of the altitude of the ozone layer above Madrid, showing that the fixed value of $22 \mathrm{~km}$ is representative for all months. Therefore, the natural variability of the altitude of the ozone layer over the Iberian Peninsula presents a very small influence in the total ozone data derived from the Brewer instruments located at this region.

\section{Conclusions}

The assumption used by the Brewer algorithm that the ozone layer is confined to a delta layer at $22 \mathrm{~km}$ results in excellent values for calculating ozone AMF at Madrid. The relative differences between the approximated ozone AMF values considered by Brewer instruments and simulated values using real ozone profiles at Madrid are completely negligible for solar zenith angles smaller than $75^{\circ}$, and being lower than $2 \%$ at $85^{\circ}$. This good agreement is related to the fact that the constant altitude of the ozone layer assumed by the Brewer algorithm $(22 \mathrm{~km})$ is very close to the real altitude of the ozone mass centre at Madrid during all seasons (the average altitude of the ozone layer over Madrid is $21.7 \pm 1.8 \mathrm{~km}$ ). All these results can be extended to the Iberian Peninsula since the ozone profile above Madrid can be considered representative for this region.

Acknowledgements. The ozone profile data used in this study were provided by the Agencia Estatal de Meteorología (AEMET). This work has been partially supported by Ministerio de Ciencia e Innovación under project CGL2008-05939-C03-02/CLI and by FCT through project PTDC/CTE-ATM/65307/2006. Manuel Antón thanks Junta de Extremadura - Consejería de Infraestructuras y Desarrollo Tecnológico - and Fondo Social Europeo for concession of a postdoctoral grant.

Topical Editor C. Jacobi thanks one anonymous referee for her/his help in evaluating this paper.

\section{References}

Basher, R. E.: Review of the Dobson spectrophotometer and its accuracy, WMO Global Ozone Research and Monitoring Project, Report 13, Geneva, 1982.

Bernhard, G., Evans, R. D., Labow, G. J., and Oltmans, S. J.: Bias in Dobson total ozone measurements at high latitudes due to approximations in calculations of ozone absorption coefficients and air mass, J. Geophys. Res., 110, D10305, doi:10.1029/2004JD005559, 2005.
Iqbal, M.: An Introduction to Solar Radiation, Academic Press Canada, 1983.

Kerr, J. B., McElroy, C., and Evans, V.: The automated Brewer spectrophotometer, in: Proc. Quadrenial Ozone Symposium, Haldidiki, Greece, 396-401, 1984.

Kerr, J. B.: New methodology for deriving total ozone and other atmospheric variables from Brewer spectrophotometer direct sun spectra, J. Geopshys. Res., 107, D23, doi:10.1029/2001JD001227, 2002.

Komhyr, W. D.: Electrochemical cells for gas analysis, Ann. Geophys., 25, 203-210, 1969.

Komhyr, W. D., Grass, R. D., and Leonard, R. K.: Dobson spectrophotometer 83: A standard for total ozone measurements, 1962-1987, J. Geophys. Res., 94(D7), 9847-9861, 1989.

Marquard, L. C., Wagner, T., and Platt, U.: Improved air mass factor concepts for scattered radiation differential optical absorption spectroscopy of atmospheric species, J. Geophys. Res., 105(D1), 1315-1327, 2000.

Mayer, B. and Kylling, A.: Technical note: The libRadtran software package for radiative transfer calculations - description and examples of use, Atmos. Chem. Phys., 5, 1855-1877, 2005, http://www.atmos-chem-phys.net/5/1855/2005/.

Noxon, J. F., Whipple, E. C., and Hyde, R. S.: Stratospheric NO2, I, Observational method and behavior at midlatitudes, J. Geophys. Res., 84, 5047-5076, 1979.

Perliski, L. M. and Solomon, S.: On the evaluation of air mass factors for atmospheric near-ultraviolet and visible absorption, J. Geophys Res., 98, 10363-10374, 1993.

Redondas, A. and Cede, A.: Brewer algorithm analysis sensitivity, paper presented at the SAUNA Workshop, Puerto de la Cruz (Spain), 2005.

Sarkissian, A., Roscoe, H. K., and Fish, D. J.: Ozone measurements by zenith sky spectrometers: An evaluation of errors in air-mass factors calculated by radiative transfer models, J. Quant. Spectrosc. Radiant. Transfer, 54(3), 471-480, 1995.

Savastiouk, V. and McElroy, C. T.: Ozone and Rayleigh air mass factor calculations for ground-based spectrophotometers, paper presented at Quadrennial Ozone Symposium, Eur. Comm., Kos, Greece, 2004.

Slusser, J., Hammond, K., Kylling, A., Stamnes, K., Perliski, L., Dahlback, A., Anderson, D., and DeMajistre, R.: Comparison of air mass computations, J. Geophys. Res., 101(D5), 9315-9321, 1996.

Solomon, S., Schmeltekopf, A. L., and Sanders, R. W.: On the interpretation of zenith sky absorption measurements, J. Geophys. Res., 92, 8311-8319, 1987.

Thomason, L. W., Herman, B. M., and Reagan, J. A.: The effect of atmospheric attenuators with structured vertical distributions on air mass determinations and Langley plot analyses, J. Atmos. Sci., 40, 1851-1854, 1983.

Vanicek, K.: Differences between ground Dobson, Brewer and satellite TOMS-8, GOME-WFDOAS total ozone observations at Hradec Kralove, Czech, Atmos. Chem. Phys., 6, 5163-5171, 2006, http://www.atmos-chem-phys.net/6/5163/2006/. 